\title{
Chapter 5 \\ Research into Practice-Linking Be-7 \\ Evidence to Land Management Policy \\ Change for Improved Food Security
}

\author{
M. Benmansour, W. H. Blake and L. Mabit
}

\subsection{The Importance of the Short-Term Perspective for Land Management Policy Makers}

The short-term perspective on soil redistribution in the landscape offered by ${ }^{7} \mathrm{Be}$ is essential to policy makers with responsibility for developing efficient land management strategies to support food and water security. Soil conservation is vital for enhancement of food production on hillslopes of agroecosystems. Mobilisation of eroded soil and transfer downstream leads to siltation of river channels, lakes and reservoirs, which presents a credible threat to river basin ecosystem service provision and water security. In addition, energy security is threatened by siltation behind hydropower dams. The short-term perspective of this cosmogenic radioisotopic tool means it can provide relatively rapid assessment of very recent changes in practice. Because of its agro-environmental behaviour, this short-lived radioisotope a reliable natural isotopic tracer to assess the effectiveness of recent soil conservation strategies (Mabit et al. 2008; Taylor et al. 2013).

The key challenge that many policy organisations face is obtaining convincing and scientifically sound evidence upon which realistic and wise informed decisions can be based. While many conventional methods are capable of determining on site

\footnotetext{
M. Benmansour

Centre National de l'Energie, des Sciences et des Techniques Nucléaires (CNESTEN), Rabat, Morocco

e-mail: benmansour64@yahoo.fr
}

W. H. Blake

School of Geography, Earth and Environmental Sciences, University of Plymouth, Plymouth, UK e-mail: william.blake@plymouth.ac.uk

\section{Mabit $(\varangle)$}

Soil and Water Management and Crop Nutrition Subprogramme, Joint FAO/IAEA Division of Nuclear Techniques in Food and Agriculture, International Atomic Energy Agency, Vienna, Austria

e-mail: L.Mabit@iaea.org 
erosion rates at a point (e.g. rainfall simulation, erosion pin measurements, survey techniques), the scaling of these measurements to the wider hillslope or landscape unit is challenging. This is especially the case given that equipment associated with many conventional approaches interferes with either farming activities themselves or natural soil erosion processes.

An advantage of ${ }^{7} \mathrm{Be}$ is that this isotopic tracer is integrated into the natural hydrological cycle. Delivered naturally via rainfall to the soil surface and redistributed via erosion processes, it operates without any interference by deployment of measurement equipment. In addition, the method can be applied retrospectively and sampling strategies driven by field observations after an erosion event. The method is not without complications and challenges but if undertaken with care and due attention to assumptions and limitations (as described in Chaps. 1-4), the above advantages offer opportunity to gain critical information on soil and sediment redistribution to support policy decisions on soil conservation and environmental management.

\subsection{Linking Nuclear Techniques in Soil Erosion and Conservation to Policy Change}

Early studies conducted in the 1990s outlined the principles and opportunity for use of ${ }^{7} \mathrm{Be}$ as a soil erosion and soil redistribution tracer (Wallbrink and Murray 1996; Blake et al. 1999; Walling et al. 1999; Blake et al. 2002). This foundation-laying research has since had a wider impact on soil conservation and environmental management policy through applied studies of the method around the world. This has been facilitated by research development and refinement performed within IAEA's Coordinated Research Projects (CRPs) such as the CRPD1.50.08 "Assess the effectiveness of soil conservation techniques for sustainable watershed management using fallout radionuclides" (2002-2008), the CRP D1.20.11 "Integrated Isotopic Approaches for an Area-wide Precision Conservation to Control the Impacts of Agricultural Practices on Land Degradation and Soil Erosion" (2009-2013) and more recently through the on-going CRP D1.50.17 "Nuclear Techniques for a Better Understanding of the Impact of Climate Change on Soil Erosion in Upland Agro-ecosystems" (2016-2021). Following the CRPs activities, several guidelines were produced by the SWMCN Subprogramme of the Joint FAO/IAEA Division of Nuclear Techniques in Food and Agriculture (e.g. IAEA 2014; Mabit et al. 2018).

Impact on policy has been further extended worldwide to several IAEA Member States and FAO Member Countries by methodology transfer and capacity-building activities within IAEA national and/or regional technical cooperation projects (e.g. RAF5075 "Enhancing Regional Capacities for Assessing Soil Erosion and the Efficiency of Agricultural Soil Conservation Strategies through Fallout Radionuclides in Africa") which includes targeted training courses on the use of ${ }^{7} \mathrm{Be}$ as a tracer to support soil conservation policy by leading researchers. As a result of these outreach and science-policy impact activities, application of this specific methodology 
has been extended to a range of soil conservation challenges, in collaboration with national and international organisations responsible for environmental management policy to support food and water security or management of forest resources.

For example, Blake et al. (2009) undertook a landscape sediment budget approach with ${ }^{7} \mathrm{Be}$ alongside ${ }^{137} \mathrm{Cs}$ and ${ }^{210} \mathrm{~Pb}$ to evaluate the post-fire loss of topsoil and nutrients from forest affected by wildfire to a major water supply reservoir in Australia, in collaboration with the government agency responsible for developing policy on fire management for water quality and quantity. Under future climates, wildfire will exacerbate threats to water security. The applied fallout radionuclide (FRN) research demonstrated that burning of surface vegetation can invigorate hillslope hydrological response with marked increases in sediment and nutrient delivery to river networks and reservoirs. Negative water quality effects include for example high turbidity, toxic algal blooms and fish kills with implications for water supply at critical times in the water year. Through quantifying post-fire runoff and nutrient yield processes, the research informed catchment management decisions, policies and water resource risk assessment in Australia. Similarly, researchers in Chile, applied ${ }^{7}$ Be using a transect approach (Schuller et al. 2006) for evaluation of the impact of forest harvesting on soil erosion fine sediment yields and for contribution to improve the effectiveness of mitigation measures before, and after clear-cut operations and during the establishment of the new plantations. This work demonstrated the benefit of using ${ }^{7} \mathrm{Be}$ to document the effects of recent forest clearance upon slope soils in a timber harvesting operation. The short-term perspective of ${ }^{7} \mathrm{Be}$ meant the use of mitigation strategies could be assessed and, in this case, a high sediment delivery ratio indicated to policymakers the need for further soil conservation strategies.

\subsection{Example Impact Case Study: Support Provided by The ${ }^{7}$ Be Technique to Shape Soil Conservation Policy in Morocco}

\subsubsection{Soil Erosion and Conservation Policy Challenges in Morocco}

Soil erosion is the main land degradation process in Morocco, which is affecting up to $40 \%$ of its land area. About two million hectares of Moroccan agricultural lands are affected by soil erosion by water (Dahan et al. 2012). On average, soil erosion ranges from 5 to $20 \mathrm{t} \mathrm{ha}^{-1} \mathrm{yr}^{-1}$, but exceeds these magnitudes in northern and north-western basins. For example, in the pre-Rif hills region, soil erosion exceeds $50 \mathrm{t} \mathrm{ha}^{-1} \mathrm{yr}^{-1}$ (HCEFLCD 2017). Out of a total area of 20 million ha of watershed in Morocco, $50 \%$ is estimated to be subjected to very high erosion risks with a yearly soil loss of around 100 million tons. This annual soil loss leads to a reduction of 75 million $\mathrm{m}^{3}$ of downstream dam water storage capacity. Each year about $0.5 \%$ of the country's reservoir storage capacity is lost. These soil erosion 
and conservation challenges require both spatially representative data on soil erosion amounts and sediment delivery ratios. The highly dynamic nature of land use change and implementation of new conservation policies, however, means that longor medium-term FRN approaches are not recommended to deliver the data required by policymakers on the extent of the problem and the level of success in conservation approaches applied (Mabit et al. 2008). Consequently, researchers in Morocco have been using the ${ }^{7} \mathrm{Be}$ methodologies outlined in this book to tackle these challenges and the obtained data have been used to assist development of new soil conservation policy in a wide range of settings.

\subsubsection{From the Laboratory to the Field: The Approach}

FRN methodologies have been successfully used by the "Centre National de l'Energie, des Sciences et des Techniques Nucléaires" (CNESTEN) in many cultivated areas of Morocco for supporting soil conservation strategies tested or implemented by the government. The research has shaped soil conservation policy with the collaboration of "Institut National de Recherche Agronomique (INRA) from the Ministry of Agriculture and Maritime Fisheries and "Centre de Recherche Forestière" (CRF) from the "Haut Commissariat des Eaux et la Lutte contre la Désertification" (HCEFLCD). Fallout ${ }^{7} \mathrm{Be}$ was applied in combination with ${ }^{137} \mathrm{Cs}$ and ${ }^{210} \mathrm{~Pb}$ to estimate soil erosion in agricultural or forest fields under different land uses in the regions of Rabat, Tétouan, Casablanca and Fes (Fig. 5.1) both before and after implementation of recommended soil conservation approaches. The transect sampling strategy was generally adopted (see Chap. 2) and FRNs were determined at CNESTEN Laboratory using gamma detectors (see Chap. 3). Key studies where the ${ }^{7}$ Be approach has been integrated into policy-development research:

(1) In semi-arid and Mediterranean climatic areas (Rabat and Tétouan regions), a no-till technique was tested as a soil conservation practice and compared to conventional tillage in the experimental sites "Marchouch" and "Herchane" of the region of Rabat and Tétouan respectively;

(2) In semi-arid climatic areas (Casablanca-Settat region), ${ }^{7} \mathrm{Be}$ was used to evaluate the efficiency of conservation practices involving Atriplex plantations (implemented based on results from other FRNs) and, cereal and fruit plantations effectiveness were assessed within the "Oued Mellah" watershed management programme;

(3) In variable climatic areas from cold-humid to semi-arid climate (Fes region), the efficiency of soil conservation practices based on the use of Allepo pine trees combined with dry stones and gabion and also fruit plantations was assessed within the framework of the "Allal Fassi" watershed management programme. 


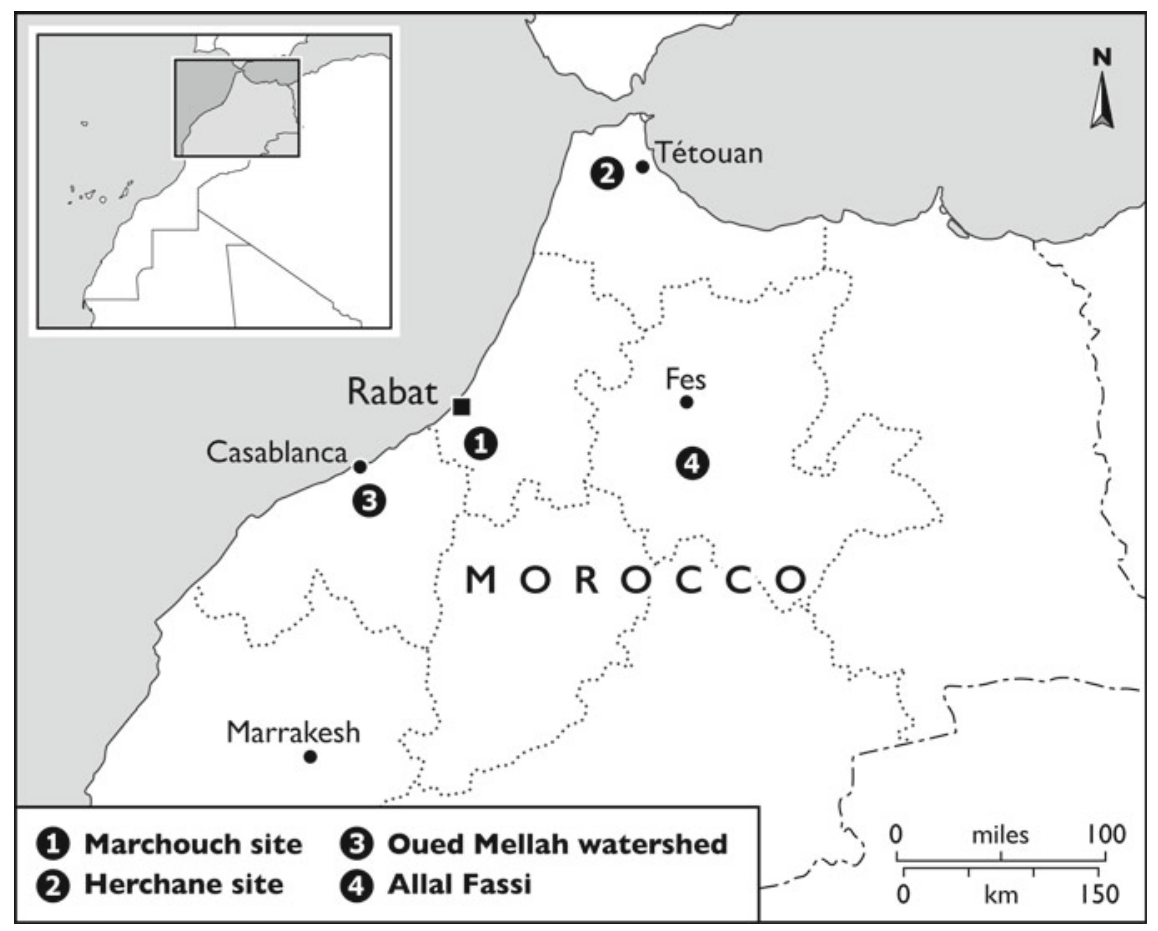

Fig. 5.1 Locations of the study areas = (1) Marchouch site (region of Rabat), (2) Herchane site (region of Tétouan), (3) Oued Mellah watershed (region of Casablanca) and (4) Allal Fassi (region of Fes)

\subsubsection{Key Findings and Policy Impacts from ${ }^{7}$ Be Application in Morocco}

Previous investigations using other FRNs $\left({ }^{137} \mathrm{Cs}\right.$ or $\left.{ }^{210} \mathrm{~Pb}_{\mathrm{ex}}\right)$ allowed establishment of the long-term soil erosion rates of the three investigated regions, which ranged from 8 to $58 \mathrm{t} \mathrm{ha}^{-1} \mathrm{yr}^{-1}$ (Benmansour et al. 2013; Benmansour et al. 2016; Yassin et al. 2017). The net soil erosion rates appeared to be closely related to the rainfall, slope and the past land use. The sediment delivery ratio in all areas is generally high reaching 80 to $100 \%$ which led to implementation of soil conservation strategies to keep fertile soil material on the hillslopes. The short-term perspective of ${ }^{7} \mathrm{Be}$ enabled the effectiveness of these soil conservation strategies to be assessed and underpinned their wider adoption in the landscape. Figure 5.2 reports the mean values of shortterm erosion amounts estimated at different study sites and corresponding to fields under conventional tillage or without management and those corresponding to fields under soil conservation practices. 
Soil redistribution data from ${ }^{7} \mathrm{Be}$ measurements indicated that soil loss had been reduced significantly under no-till as compared to conventional tillage in Rabat and Tétouan regions. Indeed, soil erosion rates were lowered by $50 \%$ for the Marchouch site (Fig. 5.2a) and by $40 \%$ for the Harchane site (Fig. 5.2b). At the Oued Mellah watershed, the results highlighted that high density Atriplex plantations reduced soil loss by approximately 57 to $80 \%$ compared to Atriplex plantations with low density while for the site under fruit plantations and cereals, soil erosion has been decreased by 58\% compared to bare soils (Fig. 5.2c). For Allal Fassi Watershed, erosion was lowered by $54 \%$ for soil under young Allepo pine, dry stones and gabions compared to soil under only Allepo pine and dry stones and by $51 \%$ for agricultural fields under cereals and fruit plantation as compared to bare soils (Fig. 5.2d). These findings have emphasised the need for wider adoption of these proven soil conservation approaches in the Moroccan landscape. Indeed, the no-till practice tested by Moroccan INRA researchers in their experimental sites is being applied and transferred by the Ministry of Agriculture to agricultural farms that have similar agro-environmental conditions as the experimental stations of INRA. The demonstrated high performance of soil conservation practices tested by HCEFLCD in the investigated watersheds means they will be adopted at a wide scale.

The relevant results derived from the application of these FRNs for short and longer-term erosion rates in Morocco were presented jointly by CNESTEN and HCEFLCD at the 12th Session of United Nation Convention for Combating Desertification, COP12, Turkey, October 2015. The impact of this research on policy was emphasised by a lead policy maker, the Head of the Forestry Research Centre of Morocco's High Commission of Forest and Water and Combating Desertification (HCEFLCD). He spoke about the role of isotopic techniques in tackling the effects of climate change, particularly drought leading to a reduction of up to $75 \%$ in grain yields: "Using isotopic techniques, we were able to accurately assess soil erosion and the effectiveness of soil conservation practices and make concrete recommendations to policy makers... These all delivered real change for people who rely on the land for their livelihoods." (IAEA 2016).

\subsection{Future Trends and Opportunities in Using ${ }^{7} \mathrm{Be}$}

The above science-to-policy examples in Morocco illustrate the fundamental role that the short-term perspective on soil redistribution rates provided by ${ }^{7} \mathrm{Be}$ can play in the development and implementation of soil erosion policy. The need for such information has never been so crucial. Against threats from soil erosion, it is predicted that global food production must increase by $70 \%$ to feed the projected growth of the world's population (from 7 to 9 billion by 2050) (FAO 2017). Extreme weather (wet and/or dry) events may become more frequent with changing global climate with impacts on soil quality and erodibility. Developing community resilience to such recurrent climatic events demands 'win-win' systems of soil conservation that permit enhancement of land productivity while protecting ecosystem services in the 


\section{(a) Machouch Site (Rabat region)}

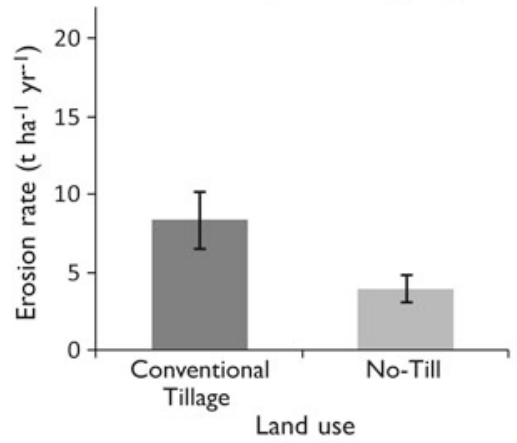

(b) Herchane site (Tétouan region)

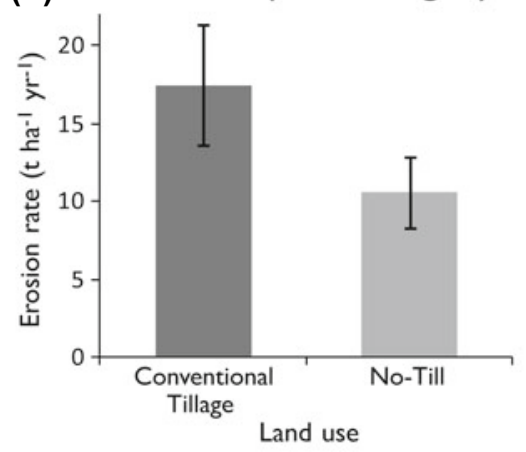

(c) Oued Mellah Watershed (Casablanca region)

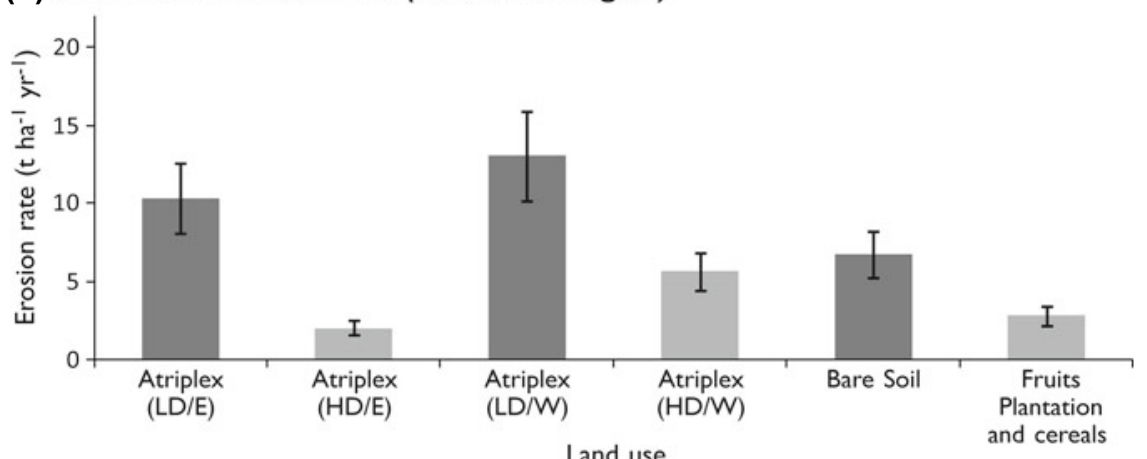

(d) Allal Fassi Watershed (Fes region)

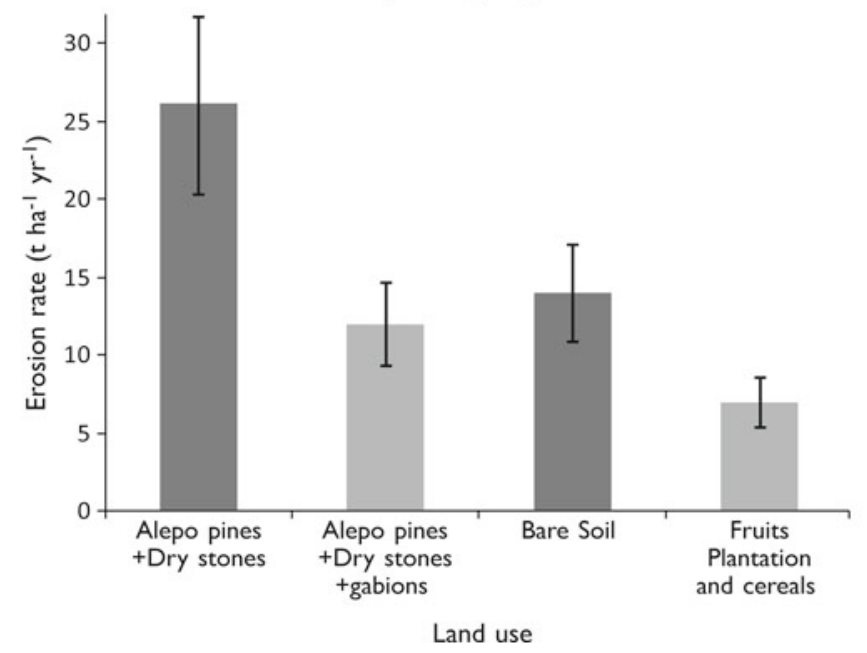

Fig. 5.2 Short soil erosion rates under different land uses associated with the study sites: Marchouch (a), Herchane (b), OuedMellah (c) and AllalFassi (d). LD Low density; HD High density; E East exposure; $W$ West exposure 
wider river basin. Key information and guidance provided by nuclear and isotopic tools such as the ${ }^{7} \mathrm{Be}$ technique provides valuable support to convince policy makers and farmers to adopt and promote widely existing effective climate smart soil conservation strategies.

\section{References}

Benmansour, M., Mabit, L., Nouira, A., Moussadek, R., Bouksirate, H., Duchemin, M., et al. (2013). Assessment of soil erosion and deposition rates in a Moroccan agricultural field using fallout ${ }^{137} \mathrm{Cs}$ and ${ }^{210} \mathrm{~Pb}_{\mathrm{ex}}$. Journal of Environmental Radioactivity, 115, 97-106.

Benmansour, M., Mabit, L., Moussadek, R., Yassin, M., Nouira, A., Zouagui, A., et al. (2016). Effectiveness of soil conservation strategies on erosion in Morocco. In Geophysical Research Abstracts (Vol. 18), European Geosciences Union-General Assembly 2016. Abstract EGU20162174.

Blake, W. H., Walling, D. E., \& He, Q. (1999). Fallout beryllium-7 as a tracer in soil erosion investigations. Applied Radiation and Isotopes, 51(5), 599-605.

Blake, W. H., Walling, D. E., \& He, Q. (2002). Using cosmogenic beryllium-7 as a tracer in sediment budget investigations. GeografiskaAnnaler Series a-Physical Geography, 84A(2), 89-102.

Blake, W. H., Wallbrink, P. J., Wilkinson, S. N., Humphreys, G. S., Doerr, S. H., Shakesby, R. A., et al. (2009). Deriving hillslope sediment budgets in wildfire-affected forests using fallout radionuclide tracers. Geomorphology, 104(3-4), 105-116.

Dahan, R., Boughala, M., Mrabet, R., Laamari, A., Balaghi, R., \& Lajouad, L. (2012). A review of available knowledge on land degradation in Morocco (p. 48). Oasis Country Report 2, International Center for Agricultural Research in the Dry Area(ICARDA).

FAO. (2017). The future of food and agriculture-Trends and challenges (163 p). FAO publication.

Haut Commissariat des Eaux et Forêts et à la Lutte contre la Désertification (HCEFLCD). (2017): http://www.eauxetforets.gov.ma.

IAEA. (2014). Guidelines for using Fallout radionuclides to assess erosion and effectiveness of soil conservation strategies. IAEA-TECDOC-1741. Vienna, Austria: International Atomic Energy Agency Publication.

IAEA. (2016). 17 Ways to change the world: IAEA promotes the role of nuclear technologies in sustainable development at European development days. Available online at https://www.iaea.org/newscenter/news/17-ways-to-change-the-world-iaea-promotes-the-roleof-nuclear-technologies-in-sustainable-development-at-european-development-days. Accessed November 2017.

Mabit, L., Benmansour, M., \& Walling, D. E. (2008). Comparative advantages and limitations of the fallout radionuclides ${ }^{137} \mathrm{Cs},{ }^{210} \mathrm{~Pb}_{\mathrm{ex}}$ and ${ }^{7} \mathrm{Be}$ for assessing soil erosion and sedimentation. Journal of Environmental Radioactivity, 99(12), 1799-1807.

Mabit, L., Bernard, C., Lee Zhi Yi, A., Fulajtar, L., Dercon, G., Zaman, M., et al. (2018). Promoting the use of isotopic techniques to combat soil erosion: An overview of the key role played by the SWMCN Subprogramme of the Joint FAO/IAEA Division over the last 20 years. Land Degradation \& Development, 29, 3077-3091.

Schuller, P., Iroume, A., Walling, D. E., Mancilla, H. B., Castillo, A., \& Trumper, R. E. (2006). Use of beryllium-7 to document soil redistribution following forest harvest operations. Journal of Environmental Quality, 35(5), 1756-1763.

Taylor, A., Blake, W. H., Smith, H. G., Mabit, L., \& Keith-Roach, M. J. (2013). Assumptions and challenges in the use of fallout beryllium-7 as a soil and sediment tracer in river basins. Earth-Science Reviews, 126, 85-95. 
Wallbrink, P. J., \& Murray, A. S. (1996). Distribution and variability of Be-7 in soils under different surface cover conditions and its potential for describing soil redistribution processes. Water Resources Research, 32(2), 467-476.

Walling, D. E., He, Q., \& Blake, W. (1999). Use of Be-7 and Cs-137 measurements to document short- and medium-term rates of water-induced soil erosion on agricultural land. Water Resources Research, 35(12), 3865-3874.

Yassin, M., Benmansour, M., Chikhaoui, M., Ismaili Alaoui, F. Z., El Bahi, S., Babaou,Y., et al. (2017). Contribution à l'évaluation de l'impact de l'aménagement des bassins versants de l'Oued Mellah et Allal El Fassi au Maroc. Annales de la Recherche Forestière au Maroc, 44, 79-96.

The opinions expressed in this chapter are those of the author(s) and do not necessarily reflect the views of the International Atomic Energy Agency, its Board of Directors, or the countries they represent.

Open Access This chapter is licensed under the terms of the Creative Commons Attribution 3.0 IGO License (https://creativecommons.org/licenses/by/3.0/igo/), which permits use, sharing, adaptation, distribution and reproduction in any medium or format, as long as you give appropriate credit to the International Atomic Energy Agency, provide a link to the Creative Commons licence and indicate if changes were made.

The use of the International Atomic Energy Agency's name, and the use of the International Atomic Energy Agency's logo, shall be subject to a separate written licence agreement between the International Atomic Energy Agency and the user and is not authorized as part of this CC-IGO licence. Note that the link provided above includes additional terms and conditions of the licence.

The images or other third party material in this chapter are included in the chapter's Creative Commons licence, unless indicated otherwise in a credit line to the material. If material is not included in the chapter's Creative Commons licence and your intended use is not permitted by statutory regulation or exceeds the permitted use, you will need to obtain permission directly from the copyright holder.

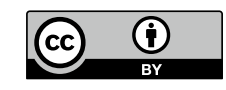

